\title{
História da reforma sanitária brasileira e do Sistema Único de Saúde: mudanças, continuidades e a agenda atual ${ }^{*}$
}

\author{
The history of the public health reform in Brazil and of the Sistema \\ Unico de Saúde: changes, continuities, and the current agenda
}

\section{Telma Maria Gonçalves Menicucci}

Professora da Faculdade de Filosofia e Ciências Humanas/Universidade Federal de Minas Gerais. Av. Antônio Carlos, 6627 31270-901 - Belo Horizonte - MG - Brasil

telmenicucci@fafich.ufmg.br
MENICUCCI, Telma Maria Gonçalves. História da reforma sanitária brasileira e do Sistema Único de Saúde: mudanças, continuidades e a agenda atual. História, Ciências, Saúde - Manguinhos, Rio de Janeiro, v.21, n.1, jan.-mar. 2014, p.77-92.

Resumo

A conferência apresenta uma retrospectiva histórica do Sistema Único de Saúde, seus antecedentes e seu legado na configuração atual, e parte da explicação de alguns de seus problemas estruturais, particularmente a convivência de um sistema público e outro privado. Busca identificar problemas que afetam sua completa consolidação, ao mesmo tempo em que chama a atenção sobre o significado profundo da implantação de um sistema único e universal em um país das dimensões do Brasil. Apontamse os efeitos do próprio Sistema, visto como uma grande transformação no campo dos direitos sociais, introduzindo novos atores no ramo da saúde e introjetando a saúde como direito. Por fim, apresentam-se desdobramentos recentes dessa história que fazem com que o Sistema esteja na agenda pública.

Palavras-chave: Sistema Único de Saúde (SUS); história do SUS; legado da política de saúde; efeitos do SUS.

\section{Abstract}

The paper offers a historical retrospective of Brazil's Sistema Único de Saúde (SUS), including its background and its legacy on its current design. It begins describing some of the system's structural problems, especially the co-existence of a public system alongside a private one. It identifies problems that have hampered a firmer solidification of SUS, while it also highlights the immense import of establishing a unified, universal system in a country the size of Brazil. The discussion includes the effects of the system, which has represented a major change in the field of social rights, introducing new actors, and internalizing the notion of health as a right. Lastly, recent developments that have put SUS on the public agenda are discussed.

Keywords: Sistema Único de Saúde (SUS); history of SUS; health policy legacy; effects of SUS. 
É sempre muito bom refletir sobre o Sistema Único de Saúde, o SUS, uma das histórias

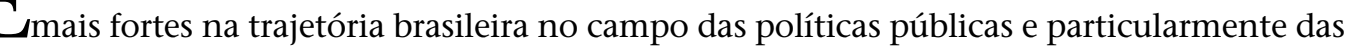
políticas sociais. Participei de uma reflexão quando o SUS fez vinte anos, e eu diria que hoje, aos 25 anos, podemos identificar algumas mudanças naquilo que apontamos há cinco anos. Os problemas permanecem, mas do ponto de vista político há alguns sinais de mudanças importantes no sentido de que o SUS volta para a agenda de discussão. Esse é um argumento que tentarei defender.

Apresentarei brevemente os antecedentes do SUS que explicam o formato que ele adquiriu e os problemas que disso decorrem. Farei isso sob uma perspectiva histórica, analítica, tentando entender o hoje a partir do encadeamento de decisões do passado. Então, a linha de minha reflexão buscará identificar os antecedentes que levaram à criação do SUS como principal instituição da política de saúde do Brasil, alguns problemas estruturais que afetam seu desenvolvimento e sua completa consolidação, bem como alguns desdobramentos recentes dessa história.

O SUS foi definido a partir de princípios universalistas e igualitários, o que é algo de fazer inveja a outros países. Estive num debate na Comissão Econômica para a América Latina e o Caribe (Cepal) agora em outubro de 2013, e todos se mostraram fascinados pelo fato de um país do tamanho do Brasil ter um sistema com princípios universalistas e igualitários - quer dizer, para todos e de forma igual - embasado na concepção de saúde enquanto direito de todos e dever do Estado. Isso não foi pouco. Essa construção do SUS rompeu com o caráter meritocrático que caracterizava a assistência à saúde no Brasil até a Constituição de 1988, e determinou a incorporação da saúde, como direito, numa ideia de cidadania, que naquele momento se expandia, e que considera não apenas o ponto de vista de direitos formais, de direitos políticos, mas principalmente a ideia de uma democracia substancial, de direitos substantivos, que envolviam certa igualdade de bem-estar. Nesse campo, cabe lembrar, a saúde teve papel preponderante no ideário de nossa Constituição cidadã.

A reforma sanitária que foi feita visando à criação do SUS, gravada na Constituição, foi de fato uma ruptura com todos os princípios que ordenavam a política de saúde até então. $\mathrm{E}$ nesse sentido podemos falar de fato em reordenamento ideológico e institucional. Ideológico devido aos princípios fundantes da política de saúde, que são completamente alterados, e institucional em função da criação do sistema único.

Como sabemos, entretanto, esse sistema inclusivo não logrou incorporar toda a população, e parte significativa dos cidadãos já estava em 1988 e continua ainda hoje fora desse sistema, abrigada em planos de saúde privados. Parece-me que dois aspectos importantes ao pensar as dificuldades do SUS quanto a ser universal e igualitário dizem respeito exatamente a essa relação de público e privado ou ao não enfrentamento dessa dualidade na assistência à saúde no Brasil. E é nesse sentido que o passado importa. Que legado temos na trajetória da política de saúde no Brasil que explica o fato de que, apesar de termos um sistema inclusivo do ponto de vista constitucional, legal, institucional, isso ainda não é uma realidade?

\footnotetext{
* Este depoimento é uma transcrição da conferência proferida em 24 de outubro de 2013, no "Encontro às quintas", do Programa de Pós-graduação em História das Ciências e da Saúde da Casa de Oswaldo Cruz (COC)/Fiocruz. Participou do debate o pesquisador José Carvalho Noronha, do Instituto de Comunicação e Informação Científica e Tecnológica em Saúde/Fiocruz.
} 
Retomarei muito rapidamente uma história que vocês conhecem, mas, me parece, dá sentido ao argumento que defenderei. Nossa política de saúde foi constituída de forma segmentada desde seu nascedouro. A assistência à saúde eclode na previdência social, que foi o marco básico do sistema de proteção social montado no Brasil. Foi por meio da previdência social que se desenvolveu a sustentação dos direitos sociais pelo Estado. E essa previdência, quando surge, já traz a segmentação de suas clientelas. Inicialmente nas Caixas, ligadas às empresas, e depois nos Institutos de Aposentadorias e Pensões, os IAPs, construídos em torno de categorias profissionais, sendo que cada Instituto prestava também residualmente assistência à saúde - o que, aliás, dá origem à assistência à saúde propriamente -, mas de formas diferenciadas. Então, cada instituto tinha mais ou menos recursos para a saúde e prestava serviços de maior ou menor envergadura.

O mais importante nessa história é que o benefício era vinculado ao contrato de trabalho formal, tendo as características de seguro e não de direito de cidadania. Nesse sentido, revestese do caráter meritocrático vinculado à inserção no mercado de trabalho, cujas diferenciações reproduz. Além disso, a política de saúde brasileira apresentava diferenciação funcional e institucional: ao Ministério da Saúde cabiam as ações de caráter coletivo e algumas de assistência básica, e à Previdência Social, a saúde curativa restrita aos segurados.

Aspecto importante dessa origem, que também explicará um dos problemas posteriores, diz respeito ao crescimento da assistência da previdência social, que amplia gradativamente sua cobertura - depois das Caixas e dos IAPs, ocorre em 1966 a unificação de todos os Institutos no Instituto Nacional de Previdência Social, INPS, o que significou a cobertura de todos os assalariados urbanos; portanto, expansão muito grande também da assistência médica. A opção política dos governos para dar conta dessa ampliação de cobertura foi não prover os serviços diretamente, mas comprá-los da rede privada. Nesse sentido, então, a política pública voltada para a saúde incentivou o desenvolvimento do mercado privado de saúde, tanto pela compra de serviços quanto pelos subsídios do governo para construção de unidades hospitalares. Fundamental também para entender a trajetória posterior da dualidade do sistema brasileiro foi a estratégia de fazer convênios com empresas que, por meio de subsídios governamentais, do então INPS, se encarregassem da prestação de assistência à saúde a seus empregados. Esse é o berço dos planos de saúde, porque desenvolveu nas empresas a prática de prestar serviços aos empregados, o que gerou no mercado outra modalidade institucional: as empresas médicas que geriam a assistência médica para as empresas empregadoras. Inicialmente as empresas empregadoras fazem isso em seus setores de pessoal, mas depois terceirizam para empresas médicas; posteriormente, como reação às empresas médicas, ainda surgem as Unimeds, cooperativas de trabalho médico, com igual atuação, mas tendo o trabalho sob controle dos médicos e não de empresários de outros setores.

Se num primeiro momento essa dinâmica é atrelada à política pública, por meio dos convênios, posteriormente as empresas tornam-se independentes do governo e passam a prescindir de seus incentivos financeiros. Então, se num momento a assistência empresarial era complementar à assistência pública, passa a ser suplementar, ou seja, passa a ter independência, vida própria e adquire importância como política de pessoal, passando a fazer parte, aliás, das negociações coletivas dos trabalhadores, que reivindicam mais e mais planos de saúde 
empresariais. A consequência política disso para o SUS é muito grande, uma vez que perde significativo apoio de um ator político que é exatamente a massa de trabalhadores organizados.

Daí advêm consequências muito complexas. As decisões de políticas do passado explicam por que na Constituinte teremos forte embate entre os novos atores - os novos sujeitos coletivos, que se organizam a partir de meados da década de 1970 no Brasil, o chamado movimento sanitário, com propostas inovadoras no sentido de um sistema de saúde universal e de caráter igualitário - e os atores forjados na trajetória da política de assistência à saúde no Brasil que, bastante consolidados, tinham desenvolvido instituições importantes, comportamentos e até mudança da percepção das pessoas, dos trabalhadores organizados, que passam a gostar de estar em planos de saúde; as empresas fizeram investimentos, e isso se transformou num grande negócio. Já tínhamos, portanto, vários atores e ações bastante institucionalizadas, e o mercado na década de 1980 está forte e institucionalizado. Essa trajetória de desigualdades terá consequências também na corporativização dos nossos trabalhadores, desde o percurso da previdência social, que é corporativizada por categorias, até, adiante, nos próprios planos de saúde. No caso da assistência à saúde, há igualmente grande diferenciação entre trabalhadores, de acordo com a região, porque esses se desenvolverão mais nas grandes empresas, tanto nacionais quanto multinacionais, e no eixo Sul-Sudeste, onde estão as maiores empresas e se verificam as melhores condições salariais e de emprego, bem como o acesso diferenciado à assistência à saúde.

Além dos convênios, é importante chamar a atenção para a decisão, também da década de 1980, quanto aos incentivos fiscais dados inicialmente às empresas empregadoras para deduzir de seus lucros o gasto com a assistência à saúde para seus empregados e, portanto, obter redução no imposto de renda. Posteriormente, quando o mercado se expande também fora das empresas, vendendo planos de saúde individuais, verificaremos mais uma vez os incentivos fiscais para pessoas físicas, a renúncia fiscal, podendo ser descontados no imposto de renda os gastos com a saúde.

É fácil entender que os incentivos fiscais são oferecidos exatamente quando se quer incentivar determinado comportamento. Fácil também é entender a consequência do crescimento dos planos de saúde, em parte então financiados pelo governo, porque os incentivos fiscais podem ser contabilizados como gastos públicos - o que deixa de ganhar constitui gasto: a expansão bastante acentuada do segmento privado de forma autônoma a partir dos anos 1960 e particularmente na década de 1980, exatamente quando há um processo de democratização que colocará em cena outros atores políticos e permitirá o surgimento de projetos alternativos de política de saúde que rompiam com essa lógica.

É bom lembrar que a reforma sanitária vem desse movimento de diferentes atores na sociedade: a categoria médica, as associações médicas, o movimento popular em saúde, os partidos de esquerda, então na clandestinidade, o apoio da Igreja por meio das comunidades eclesiásticas de base e vários parlamentares, que passam a ter significativa atuação no Congresso. Esse movimento, portanto, conseguiu colocar em pauta uma proposta bem definida e clara de reforma da saúde.

A própria lógica da Constituição de 1988, repito, amplia bastante os direitos - não é à toa que Ulysses Guimarães a chamou de Constituição cidadã - entre eles os referentes à saúde, deixando transparecer a clara intenção de uma proposta de reforma vigorosa. 
Evidenciaram-se na Constituição as visões antagônicas desses dois grupos de atores. $\mathrm{Na}$ época, suas posições eram simplificadas em dois termos: a estatizante, que era a perspectiva inovadora, daqueles que queriam a reforma da saúde, uma reforma no sentido de assumir o direito à saúde como obrigação a ser provida pelo Estado; e a privatizante, que representava os interesses e concepções surgidos na trajetória da política de saúde como efeito de feedback das próprias decisões governamentais do passado. Nesse sentido, as decisões de políticas públicas forjaram determinados atores e interesses que se colocarão como importantes pontos de veto no momento da votação da Constituição, cujo texto refletiu os acordos que se conseguiu construir naquele momento. Ele apresenta, aliás, algumas ambiguidades jurídicas que apontam o ajustamento dessas alternativas inovadoras aos padrões consolidados. Como resultado a Constituição apresenta um sistema híbrido e segmentado: por um lado consagra a saúde como direito, garante a universalidade e acesso à assistência, amplia a responsabilidade estatal e define a estruturação de um sistema inclusivo; por outro, preserva a liberdade do mercado e garante a continuidade das formas privadas de assistência e independentes de qualquer intervenção governamental. Essa intervenção, via regulação do setor privado, só ocorrerá no final da década de 1990: em 1999, pela lei que regulamenta os planos privados, e em 2000 pela criação da Agência Nacional de Saúde Suplementar (ANS). Curiosamente, no momento em que se fazia o esforço hercúleo de se implementar a política de saúde definida na Constituição, verifica-se a entrada na agenda governamental e pública da regulamentação dos planos privados de saúde, o que acontecerá no final da década de 1990.

Houve, portanto, de fato uma situação de ruptura com os princípios que embasavam a política de saúde, mas também alguma continuidade; uma confluência de fatores favoreceu a inovação institucional - entre eles o processo de democratização no bojo do qual foram possíveis a democratização da saúde e a constituição de novos atores coletivos devido a um momento de desequilíbrio institucional no processo de refundação do pacto político brasileiro. Tem-se um momento de inovação institucional, que conflui, entretanto, com um legado das políticas prévias de certa forma limitador da possibilidade de mudança completamente radical. A mudança faz-se então limitada em alguma medida pela estrutura antiga e não é capaz de desmontá-la. Constituiu-se de fato uma dupla trajetória: pública e privada.

Passarei rapidamente por isso, apenas pontuando alguns aspectos importantes, uma vez que o texto constitucional é bastante conhecido:

(1) A saúde é vista como parte da seguridade, ou seja, trabalha-se com a ideia de atenção do berço até a morte, e uma lógica universalista e equitativa da seguridade social.

(2) Adota-se um conceito de saúde como articulação de políticas sociais e econômicas que não se restringe à assistência médica. Abro aqui um parêntese: uma ocasião, refletindo sobre saúde no governo Lula, cheguei à conclusão de que na saúde mesmo tinham ocorrido ações incrementais, embora algumas novidades, inovações. O mais importante do governo Lula, do meu ponto de vista, foi a mudança na qualidade de vida. Políticas visando diminuir a desigualdade, políticas de saneamento, habitação, alimentação, segurança alimentar, uma série de ações que de fato melhoram as condições de saúde. Entendo que o governo foi eficaz em melhorar as condições de saúde no sentido que está na Constituição, que é a articulação de políticas sociais e econômicas que diminuam o risco de adoecer, o que não se restringe à assistência médica. 
Retomando os aspectos relevantes:

(3) a Constituição define saúde como direito social e universal;

(4) as ações em serviço de saúde são caracterizadas como de relevância pública, cabendo ao poder público dispor sobre sua regulamentação, fiscalização e controle que permite priorizar a saúde - o controle é algo em que precisamos avançar: o que significa isso? que tipo de regulação é essa?;

(5) ocorre a criação do SUS, organizado segundo as diretrizes de descentralização, atendimento integral e participação da sociedade. Isso não é pouco. É preciso defender esse gigante que é o SUS num país do tamanho do Brasil, em que de fato se efetivou uma descentralização. Antes havia o Instituto Nacional de Assistência Médica da Previdência Social, o Inamps, órgão federal completamente centralizado, e o SUS vai para os cinco mil e tantos municípios brasileiros, concretizando a ideia do atendimento integral em todos os níveis de complexidade da atenção; e da participação da sociedade, que reflete todo o contexto de democratização, da ação de movimentos sociais para ampliação da democracia.

(6) Simultaneamente, porém, a constituição define que a iniciativa privada é livre no setor, com garantias que contrariam o espírito da oitava Conferência, o caráter complementar do setor privado prestador de serviço. Com isso, priorizou-se a rede pública e privada sem fins lucrativos.

(7) Vedou-se a destinação de recursos públicos para auxílios e subvenções em instituições privadas com fins lucrativos, mas não se tratou da questão dos subsídios indiretos ao sistema de saúde privado. Isso ficou no campo da não decisão, em que permanece até hoje.

Entrevistei alguns parlamentares recentemente, e eles declaram: quem tem coragem de falar sobre isso? Todo mundo sabe que é um absurdo, mas ninguém, nenhum deputado tem coragem de defender isso, porque, se o fizer, não ganha a próxima eleição. Todos estão a par disso, incluídos os deputados de oposição. É notória a aberração em termos de pensar o SUS, mas ninguém tem coragem de abordar a questão; politicamente é difícil ao extremo, então não chega sequer a entrar em pauta.

E a última questão diz respeito ao financiamento que a Constituição decide como competência dos três entes federados, com recurso dos seus orçamentos e contribuições sociais previstas no então criado orçamento da seguridade social.

A década de 1990 assume como tarefa essa reforma arrojada, que representa uma ruptura da lógica anterior da política pública de saúde, num contexto completamente adverso. É importante ressaltar que o contexto, tanto nacional quanto internacional, foi muito desfavorável, um contexto de rediscussão do papel do Estado, de busca de um ordenamento desse papel do Estado, com francas reformas pró-mercado. Como alegavam na época vários liberais, nossas reformas estavam na contramão da história: o mundo todo discutindo a diminuição do papel do Estado e nós implantando uma Constituição que ampliava o papel do Estado e a responsabilidade estatal na provisão de várias políticas públicas. Era, portanto, um contexto de defesa de políticas focalizadas e de restrição a políticas universalistas. E o mais grave no aspecto ideológico era esse contexto de crise fiscal e econômica, que levou a várias políticas de ajuste, com cortes das despesas públicas, particularmente das despesas com políticas sociais. É também o momento de reestruturação da relação entre Estado e mercado, defendendo-se uma 
relação virtuosa entre ambos e atribuindo-se ao Estado, aliás, o papel subsidiário, ou seja, de atuar quando o mercado não desse conta. É esse, então, o contexto normativo e ideológico da época, que teve influência no SUS, na implantação da política de saúde.

Além desses efeitos de contexto econômico, ideológico e político, porém, há os que eu mencionei antes, efeitos institucionais da política prévia, efeitos de feedback do passado que se expressaram no contexto de implementação do SUS. Um suporte político insuficiente para a reforma. O movimento sanitário, lógico, envolvido na concretização da reforma; fazendo parte da burocracia pública; ocupando lugares importantes, mas sem grande mobilização... Ainda assim, se não fosse a nona Conferência, nada se implantaria, pois o Collor não regulamentaria nunca: havia briga dentro do governo, discordâncias sobre o SUS, defesa do Inamps pela burocracia central muito forte.

Foi insuficiente, entretanto, o suporte político, no sentido de movimentos populares, movimentos sindicais, os próprios pós-reforma, pós-democratização; aquele movimento coeso se divide nas várias clivagens partidárias, nos vários partidos que a democratização permitiu. O movimento médico, que tinha sido muito importante no apoio à reforma sanitária, volta-se para suas questões coorporativas e se afasta da questão maior. Não havia, portanto, de fato coalizões amplas para a implementação de uma reforma de cunho universalizante. Políticas de caráter universal, que são altamente redistributivas na sua concepção e natureza, demandam coalizões políticas amplas para sua implementação, e isso não existia.

Outro grande problema era o subfinanciamento; os recursos para a reforma, que já não eram tantos, não foram significativamente ampliados para implementar reforma dessa envergadura. Mais do que isso, eles não foram sequer ampliados. Em função das crises econômicas e das questões políticas, durante a década de 1990 houve muita instabilidade na alocação dos recursos federais, muitos contingenciamentos no orçamento da saúde.

Outro efeito de feedback recai sobre a rede de serviços, como já mencionei. Configura-se, nesse sentido, setor público altamente dependente da rede privada prestadora de serviços, com baixíssima experiência de regulação, trajetória de corrupção e de assolamento do próprio Estado, bem como de ocupação do Estado pelos interesses privados, o que fez com que o governo não desenvolvesse a capacidade de regulação do serviço privado, limitando-se a regulação praticamente à definição de preços e de tetos financeiros. O problema, me parece, não é a rede ser privada ou pública. O importante é que se consiga garantir o interesse público, sua prevalência sobre os interesses privados, o que se faz por meio da regulação, o que ainda hoje é bastante frágil, em decorrência do efeito de feedback.

A implementação do SUS, repito, ocorre paralelamente à discussão da assistência médica supletiva, constituída pelos planos privados de saúde. A própria expressão assistência médica supletiva demonstra esse caráter separado, independente da assistência pública. Foi criada a agência reguladora.

$\mathrm{Na}$ época alguns autores alegavam que isso era a privatização da saúde. Discordo dessa análise, porque a privatização via planos de saúde vinha desde os anos 1960. Não se tratou de privatizar o que era público; pelo contrário, configurou-se a intervenção do Estado num mercado que se desenvolvera à margem de qualquer regulação governamental; apenas autorregulado. Nesse sentido, a ANS e toda a legislação ampliam a intervenção do governo num mercado sem nenhuma regulação. 
A lógica dessa política de regulação dos planos privados foi exatamente contrária à do SUS, de estimular o mercado e proteger o consumidor, e não o cidadão, dos efeitos da ética utilitarista do mercado.

Entendo que a política regulatória explicita de maneira legal e institucional o fato de que os princípios do SUS de universalidade e igualdade eram formais. O modelo regulatório, da forma como foi adotado, suplementar e não uma articulação, um mix público-privado, como se diz hoje (não sei bem o que isso significa...). Sua implantação, de qualquer forma, foi separada: regula esse mercado, e o SUS é outra história, com outra regulação e mecanismos decisórios totalmente díspares. São modelos e concepções diferentes: um é direito do consumidor e defende o mercado; o outro é direito de cidadania, obrigação do Estado. Num os mecanismos institucionais de decisão envolvem a participação da sociedade por meio dos conselhos; noutro há uma instância técnica de que o conselho participa, dá palpite, mas não decide. Quem decide na ANS não é o conselho, mas uma instância considerada técnica. Nos moldes da discussão de gestão pública da época, em que a agência reguladora é sempre pensada como unidade pseudotécnica, que vai defender o interesse das operadoras e dos consumidores de forma técnica e neutra, tendo como mecanismo de accountability, de responsabilização, mecanismos de controle de resultados, da eficiência do serviço e não os mecanismos políticos de controle por parte da sociedade. Trata-se, portanto, de outra lógica, completamente diferente.

Tem-se, então, formalmente, o que chamo de segmentação de clientelas, que promove assistência pública prioritariamente para os segmentos sociais que não têm capacidade de adquirir plano de saúde ou os que estão excluídos dos planos coletivos, que constituem a maioria dos planos atuais.

Esses são apenas alguns dados para mostrar as consequências desse formato institucional público-privado em relação ao perfil dos usuários. Há cerca de $25 \%$ de cidadãos com plano de saúde segundo dados recentes do Sistema de Informação de Beneficiários (SIB)/ANS ${ }^{1}$, percentual, entretanto, que permanece constante desde o primeiro levantamento realizado, que foi a Pesquisa Nacional por Amostra de Domicílios (PNAD), de 1998. ${ }^{2}$ Essa foi a primeira vez que se obtiveram dados sistematizados quanto ao volume de usuários de plano de saúde no Brasil. Eram 24\% ou 25\% e continuam a ser até hoje, o que fornece quadro profundamente desigual: concentram-se na região Sudeste, depois na região Sul, e muito pouco na região Norte. Há, portanto, uma divisão muito grande, concentração nas capitais e baixíssima cobertura no interior do país.

Essa cobertura por planos tem certa relação com rendimento. A maior concentração se refere às pessoas que ganham mais de cinco salários mínimos, o que, entretanto, não tem a ver com a aquisição de planos no mercado, mas com a inserção privilegiada no mercado de trabalho, porque os planos são coletivos. Então, quem trabalha numa empresa grande e que paga bem vai ter plano de saúde, conforme dados da PNAD de 2008.

\footnotetext{
${ }^{1}$ Brasil, Ministério da Saúde, Agência Nacional de Saúde, Sistema de informações de beneficiários, dez. 2012, disponível em: www.ans.gov.br/.

2 Brasil, Ministério do Planejamento, Orçamento e Gestão, Instituto Brasileiro de Geografia e Estatística, Diretoria de Pesquisas, Instituto Brasileiro de Geografia e Estatística, Pesquisa nacional por amostra de domicílios 1998, disponível em: www.ibge.gov.br.
} 
Com relação ao financiamento, os últimos dados disponíveis na nota técnica n.26/2013 da Consultoria de Orçamento e Fiscalização Financeira (Conof) mostram que os recursos privados alocados na saúde já superaram os recursos públicos. ${ }^{3}$ Dado de 2011 mostrava que, do gasto total com saúde, os recursos públicos eram da ordem de 45,74\%; o restante já era do setor privado. E nós temos sistema público universal. Juntos, o gasto privado e o público correspondem a 8,9\% do Produto Interno Bruto (PIB); as despesas públicas, a 4,07\% do PIB. Isso é considerado pouco por todos os analistas. É pouco em qualquer país. É pouco principalmente comparando com países que têm sistemas universais como o brasileiro. Alguns exemplos da nota técnica da Conof: no Canadá o gasto público é $70 \%$ do gasto total; no Reino Unido, 82,7\%; na Argentina, 60\%. Então, temos um sistema público, universal, mas o gasto privado é mais alto.

Carlos Octávio Ocké-Reis, na nota técnica n.5 do Instituto de Pesquisa Econômica Aplicada do Rio de Janeiro (Ipea), analisou algo pouco abordado: gastos tributários associados ao mercado de planos de saúde; e calculou a renúncia fiscal no período de 2003 a 2011, a fim de saber quanto, por meio da renúncia fiscal, o governo está de fato gastando com saúde privada. ${ }^{4}$ A renúncia fiscal, naturalmente, inclui plano de saúde, desonerações fiscais para a indústria farmacêutica, no caso de remédios, e também os hospitais filantrópicos, que também têm desonerações fiscais.

Em 2011 o gasto tributário em saúde foi mais de oito bilhões de dólares, ou seja, 10\% do gasto tributário total, 22\% do gasto público federal em saúde. Parte disso, claro, é socialmente justo, por exemplo, as isenções fiscais para os hospitais filantrópicos, para os medicamentos; $50 \%$ desse gasto tributário, no entanto, tem a ver com planos de saúde, o que, eu diria, é socialmente injusto; $50 \%$ desse gasto tributário é com planos de saúde ou outras despesas com atendimento de saúde de pessoas físicas; $18 \%$ é relativo à assistência médica, odontológica e farmacêuticas de pessoas jurídicas a seus empregados. Se esses gastos públicos decorrentes de renúncia fiscal fossem computados, o gasto público com saúde superaria o gasto privado. Esse gasto, porém, não é direcionado exclusivamente ao setor público. Só em parte.

Outra consequência dessa dualidade é a desigualdade no acesso a serviços. Não discutirei acesso aqui, porque isso demandaria horas de discussão sobre o conceito de acesso. Mas a desigualdade de gasto afeta a oferta potencial dos serviços, e isso reflete maiores dificuldades de acesso para os dois grupos. Então, podemos de alguma maneira inferir as possibilidades de acesso por dados relativos à utilização de serviços e à oferta de serviços.

O último suplemento de saúde que se tem disponível da PNAD, o de 2008, mostrou que, das pessoas com cobertura por planos de saúde, $80 \%$ tinham feito consulta; as do SUS, só 63\%. Quanto às internações, 8,2\% dos usuários de planos privados fizeram internações, e 7\% do SUS. Não há razão para supor que quem tem plano privado seja mais doente. Portanto, isso reflete a dificuldade de acesso. Apenas $27 \%$ das mulheres dos planos privados, mas

\footnotetext{
${ }^{3}$ Dados da Organização Mundial de Saúde [OMS] citados em Brasil, Congresso Nacional, Consultoria de Orçamento e Fiscalização Financeira, Núcleo da Saúde, nota técnica n.26/2013, disponível em: http://www2. camara.leg.br/atividade-legislativa/orcamentobrasil/estudos/2013/nt26.pdf.

${ }^{4}$ Instituto de Pesquisa Econômica Aplicada, nota técnica n.5: Mensuração dos gastos tributários: o caso dos planos de saúde - 2003-2011, Brasília, maio de 2013, disponível em: http://www.ipea.gov.br/portal/images/ stories/PDFs/nota_tecnica/130528_notatecnicadiest05.pdf.
} 
53\% das usuárias do SUS nunca fizeram mamografia, embora se deva registrar que isso tem aumentado absurdamente, pois hoje é uma das prioridades da política de saúde a prevenção do câncer de mama.

Em termos de recursos esse é um grande problema, e dizemos que o SUS compete com os planos privados pelos recursos, particularmente leitos hospitalares. Como as tabelas SUS são baixas, o prestador de serviço, sempre que possível, prescinde do SUS. E não existe regulação de Estado, que, me parece, deveria haver; algo mais ou menos assim: para ter autorização de funcionamento, um hospital tem que reservar X por cento de suas vagas para o SUS. Deveria ser lei; sem isso não receberia autorização. Isso é regulação de Estado. Precisa de autorização? Qual é o órgão que autoriza o hospital? A Agência Nacional de Vigilância Sanitária (Anvisa). Então a Anvisa só autoriza se houver reserva de 10\%, 15\% das vagas para o SUS. Não é assim. Ele atende quando é do interesse do prestador, que é o que prevalece. Quando a tabela é boa, ele atende; quando não é, ele não atende. É isso que eu chamo de falta de regulação de Estado. E como o setor privado então está aí, sempre que possível o prestador prescinde do SUS ou só atende o que ele quer, quando a tabela é boa. Ora é este o debate que está aí no Ministério da Saúde: a tentativa de fazer contratos globais com os prestadores. Só se estabelece contrato para fazer tudo, e não só para ortopedia ou só para neurologia. É difícil, porque não há regulamentação de Estado que decida que saúde é relevância, e quem quiser estar nesse mercado tem de se submeter às regras do sistema público.

O número de leitos do país gira em torno de 2,35 por mil habitantes, mas só $72 \%$ deles estão disponíveis ao SUS, o que altera a cifra para 1,69 leito por mil habitantes, ou seja, apesar de $75 \%$ da população ser usuária do SUS, ela tem $72 \%$ do total de leitos disponíveis no país. No Nordeste, onde a cobertura de planos é menor, há maior disponibilidade relativa de leitos para o SUS, 84\% dos leitos da região, mas existe menor disponibilidade efetiva. Inversamente, nas regiões Centro-Oeste e Sudeste, a proporção de leitos disponíveis ao SUS é inferior à média nacional (69\% e 65\% dos leitos, respectivamente).

Com relação aos equipamentos de saúde, o quadro se repete. Esse dado é um pouco frágil porque a quantidade de equipamento não corresponde necessariamente a sua qualidade, com saldo positivo para a saúde. De qualquer forma, desses equipamentos, apenas 19\% estão disponíveis ao SUS, conforme consulta em julho de 2013 ao Cadastro Nacional de Estabelecimentos de Saúde. ${ }^{5}$ Mas se há desigualdade, o SUS é o grande prestador de serviços. Ele é responsável de fato, em termos absolutos, pela maioria dos serviços de saúde do Brasil. Cobertura total de $75 \%$ da população, em geral aqueles segmentos submetidos às piores condições de vida e saúde, e também aqueles com renda mais baixa. Mas atende o restante da população para determinados procedimentos, já que, para aqueles privilegiados, os $25 \%$, existe a dupla cobertura. Me parece que na Alemanha é assim: é possível escolher o público ou o privado; depois é possível mudar de ideia uma vez; na segunda vez, não; não se volta uma segunda vez para o público, fica-se no privado. Aqui, porém, temos a dupla cobertura, porque a lógica do SUS é essa, é de todo mundo, e é isso o que defendemos. Fica difícil você formalizar a segmentação mais radicalmente.

\footnotetext{
${ }^{5}$ Brasil, Ministério da Saúde, Cadastro nacional de estabelecimentos de saúde, jul. 2013, disponível em: http://cnes.datasus.gov.br/
} 
De acordo com a PNAD 2008, mesmo com aquelas discrepâncias entre o tipo de cobertura, $76 \%$ dos atendimentos de saúde, que significam 15,1 milhões de atendimentos realizados nas duas semanas anteriores à pesquisa, foram financiados pelo SUS, apenas $26 \%$ por plano de saúde e $18 \%$ por pagamento direto. O SUS é responsável pela maior parte dos atendimentos em puericultura, vacinação. É possível ver hoje nos postos de saúde pessoas com babás carregando seus nenéns; Mercedes parando, desce a babá, desce a mãe de sapato alto, mas está vacinando no SUS. Há outros tratamentos preventivos, o serviço de atendimento médico de urgência, o Samu, uma série de outros procedimentos pelos quais o SUS é responsável e que toda a população usa. Pronto socorro, atendimento de urgência, por exemplo. Então, o SUS de fato foi implantado, e isso não é pouco. A envergadura dessa reforma de fato alterou a lógica da política de saúde, alterou a configuração institucional do sistema público, conseguiu a unificação do comando da política nacional no âmbito do Ministério da Saúde, juntando com a integração institucional de todas as ações relacionadas a promoção, prevenção e recuperação. Rompeu a dicotomia anterior. Apesar das restrições objetivas ao acesso em função das limitações e da distribuição desigual da rede de serviços efetivou-se a universalização do acesso à população sem distinções de nenhum tipo. Apesar das restrições, reitero. O que significa a cobertura de 190 milhões de habitantes, de acordo com o censo de 2010, 75\% deles cobertos apenas pelo SUS. Ocorreu o processo de descentralização efetiva. Palmas para o movimento sanitário, para a engenharia institucional que foi montada, para o constante esforço do SUS no sentido de reorganização institucional. E assim ocorreu a descentralização, com transferência de atribuições e recursos para todos os municípios do país, 5.570 atualmente. Não é pouco, não é? O que redundou na expansão efetiva de ações e serviços públicos de saúde no território nacional.

Continuando essa mudança do sistema público, houve a implantação de um arcabouço institucional e decisório que respeita a lógica federativa. A política de saúde do SUS é copiada por outras políticas devido ao arcabouço institucional decisório, que tenta lidar com esses problemas federativos que não são só do SUS. É muito difícil implementar uma política que não focaliza um município apenas, e que envolve relação e articulação entre os entes federados, cooperação entre eles para garantir a integralidade da assistência; o arcabouço institucional e decisório, entretanto, respeita isso e vai-se aprimorando ao longo do tempo. Chamo a atenção para a criação e o funcionamento das Comissões Intergestores, com a participação dos entes federados. E, no caso da diretriz da participação social, a criação dos conselhos de saúde, que bem ou mal estão aí, uns funcionam muito bem, outros nem tanto, mas muito pior seria sem eles, que têm a participação majoritária dos usuários, porque eles têm 50\% e mais uma parte dos outros 50\% em todos os municípios e estados, além de um conselho nacional. Um arcabouço institucional e decisório, portanto, muito interessante.

Outro avanço é a grande batalha ainda não concluída. Aliás, eu diria, longe de ser alcançada, mas que visa mudar a lógica da política de saúde, antes centrada nos hospitais, fortalecendo as ações de caráter preventivo. Todo esse esforço é feito com investimentos em programas de ação básica, como parte de uma estratégia de reorganização do modelo assistencial, particularmente pelo Programa Saúde da Família, criado em 1993, e em 1996 transformado em estratégia de reorganização da atenção à saúde e estruturante dos sistemas municipais de 
saúde. Nada disso, naturalmente, funciona maravilhosamente, é suficiente, mas são coisas muito inovadoras e são muitos os aspectos relevantes a considerar.

As equipes do Programa Saúde da Família são operacionalizadas por equipes multiprofissionais, unidades básicas de saúde responsáveis pelo acompanhamento de um número definido de famílias localizadas em área geográfica delimitada. Dados de 2011 mostram que $53 \%$ da população estava coberta por equipes espalhadas por 4.847 municípios. Nos municípios maiores a cobertura é menor, em função da complexidade decorrente do fato de serem muito populosos. Por exemplo, São Paulo desconsidera as equipes do Saúde da Família na atenção básica, acreditando ter melhores soluções para esse campo.

A participação da sociedade se dá por lei, por definição legal, nas Conferências e Conselhos, também respeitando a lógica e a configuração federativa do país. Há, então, Conferências e Conselhos nos três níveis de governo. É lógico que o Brasil tem algumas, inúmeras, aliás, experiências participativas em várias áreas, em diversos momentos do ciclo das políticas públicas - formulação, implementação e avaliação - e em todos os níveis de gestão. No caso da saúde isso é importante, porque é exigência legal. Não há recursos se não houver conselho.

Em relação às instâncias decisórias e estruturas de gestão, como já mencionei, temos as instâncias de articulação entre os gestores nos vários níveis: a tripartite, que envolve os três níveis de governo, a bipartite, relativa aos estados e municípios, e mais recentemente as Comissões Intergestores regionais, no esforço de construir os espaços regionais e as redes regionais de atenção à saúde; esforço que chamo de engenharia institucional, preocupação permanente do SUS a fim de resolver o problema da universalidade de acesso e da integralidade da atenção no contexto de recursos escassos.

Então, as Conferências funcionam na avaliação e elaboração de diretrizes para a política de saúde nos níveis nacional, estaduais e municipais, e em alguns lugares, locais. Várias pesquisas mostram que a participação maior e mais consistente tem a ver com outros fatores, como o nível de associativismo da sociedade local e a abertura dos governos locais à participação. Essas duas variáveis são relevantes para explicar o melhor ou o pior funcionamento dos conselhos de saúde, que têm, à revelia do nível de desempenho, papel importante na fiscalização, na apresentação de demandas e propostas provenientes de entidades da sociedade, ainda que seja considerada baixa a capacidade de deliberação sobre o conjunto da política de saúde. E as Comissões Intergestores têm assumido papel mais significativo enquanto espaços decisórios.

O SUS também tem sido uma política de saúde extremamente rica e avançada em termos organizacionais na evolução do marco regulatório das relações federativas. Essa tarefa não é fácil, e, como mencionei, no caso de grande parte das políticas sociais, mais específica e fundamentalmente na política de saúde, o espaço municipal não dá conta de atender à integralidade e nem deve dar. Isso exige ação coletiva. Precisamos, portanto, que todos os municípios cooperem para que a atenção integral seja garantida a todos. No caso do federalismo, em que todos os municípios e estados são politicamente autônomos, não há como impor a cooperação. Então, há a necessidade de pactos, de mecanismos que incentivem a cooperação. O que é, entretanto, a cooperação? É a prática de quem tem rede atender aos outros, ser o sistema de referência. Isso demanda o que chamamos de ação coletiva, o que costuma ser muito difícil. A racionalidade individual não funciona para grandes grupos. Por exemplo, o indivíduo sozinho é racional no sentido de fazer a melhor escolha que atenda 
a seus objetivos; quando se trata de um coletivo, porém, essa racionalidade não funciona. Mesmo que seja melhor para todos os municípios a cooperação, eles não cooperam. E essa foi também a trajetória do SUS.

Na realidade do federalismo brasileiro há três níveis, três instâncias federativas, com grandes heterogeneidades estruturais e desigualdades socioeconômicas. Há uma distribuição de competências da União, mas a União é muito forte na Constituição brasileira. Ela tem mecanismos institucionais muito fortes, maior capacidade de gasto e poder regulador, normalizador da política de saúde, o que, no caso de saúde, por exemplo, está na Constituição. Isso faz com que a União tenha um poder muito grande sobre a agenda dos governos subnacionais por meio da regulação federal; apesar do significativo poder de agenda, não pode passar por cima da autonomia e não passa. Faço muita pesquisa em estados e municípios e vejo que as regras nacionais de fato afetam a agenda municipal. Todos eles vão copiando, mesmo porque as regras vêm acompanhadas de incentivos financeiros para que determinada agenda nacional seja implementada. Exemplo recente é o das redes temáticas. As redes visam assegurar ao usuário o conjunto de ações e serviços de forma efetiva e integral a partir da articulação e integração de todos os equipamentos de saúde, integrando pontos de atenção isolados. Elas pressupõem contratos de ação pública, na forma de um "termo de adesão" em que os entes federados se comprometem com determinadas ações e contam com aporte de "recursos da União" para cofinanciamento com estados e municípios para investimentos em construção, aquisição de equipamentos e custeio.

Como vem dinheiro para a constituição dessas redes, todos os municípios e estados se movimentam para fazer as redes temáticas, mas cada um faz de um jeito diferente, porque não há imposição. Não há condição de impor, porque isso fere a lógica federativa. O grande problema do federalismo, portanto, é conciliar a autonomia dos entes federados e a interdependência no SUS, que exige a inter-relação constante para a gestão de uma rede diversificada, distribuída em diferentes níveis de complexidade, territorialmente dispersa... e é preciso gerir isso. Então, a função de cooperação é importante, e a coordenação é fundamental. Se não houver coordenação de forma autônoma, a cooperação não brota. É essa a discussão. No caso a União tem esse papel, mas nas regras institucionais do SUS, na engenharia institucional que o SUS tem implementado a partir do século XXI, as regras que tentaram induzir processos de regionalização atribuem ao nível estadual de governo um grande papel de coordenação.

Esse marco regulatório do SUS também passou por fases históricas. Nos anos 1990 o foco foi na descentralização, ocorrendo então, o que se chamava de municipalização autárquica ou descentralização arco-íris (da União diretamente para os municípios): a relação do Ministério era com os municípios, desconsiderando de certa forma os estados, porque era o que se tinha a fazer no momento: descentralizar e fazer o SUS existir no âmbito total do Brasil. Isso teve como consequências não esperadas a competição entre os municípios e a distribuição ineficiente dos recursos e dos serviços de saúde. No século XXI começa a tentativa de implementar a regionalização prevista na Constituição, mas de difícil consolidação. E num contexto mais recente a ideia de pactos federativos para a construção de redes de atenção.

Então, sem me prender aos mecanismos que levaram à municipalização autárquica, focalizarei a regionalização no século XXI, que significa construir a integralidade em territórios que 
extrapolam os limites administrativos e políticos dos entes federados. E as secretarias estaduais com o papel de planejamento e coordenação desse processo tiveram muita dificuldade, porque, embora soubessem executar, depois da Constituição não executavam, nada faziam, foram esvaziadas, desmontadas.

Vários instrumentos foram criados. Na Cepal, as pessoas ficaram apaixonadas quando mencionei esses instrumentos - Plano Diretor de Regionalização, Programação Pactuada e Integrada. "Mas que maravilha o SUS!", diziam. Sim, os instrumentos são maravilhosos, mas infelizmente não funcionam. Na abordagem da questão os municípios avaliam o que têm e combinam quem faz o quê. Na prática, porém, há muita dificuldade para transformar isso em realidade. As mudanças mais recentes são exatamente no sentido de tentar formalizar esses pactos por meio de um contrato, que é o Contrato Organizativo da Ação Pública da Saúde (Coap), que contém as últimas regras e que, em princípio, aciona juridicamente o município ou o estado que o descumprir.

Cabe lembrar que se esse desenho é muito bom para a regionalização, ela ainda não é realidade, porque existe a liberdade dos atores. Destaco que o mais interessante desse desenho, me parece, está no que chamo de arenas federativas, a criação desses espaços de pactuação no âmbito micro e macrorregional com a participação de todos os municípios. Esse é um mecanismo importante. E segundo pesquisas que desenvolvi, o modo como eles compartilham decisões e tarefas acaba favorecendo a construção de identidades regionais, certa conduta com base na negociação. Passa a ser estratégico cooperar, posto que a não cooperação é criticada, comentada e tornada pública. Esse aspecto está longe de ser alcançado, mas é bastante interessante.

Há algumas dificuldades. O arranjo é interessante. Mas que outros fatores, independente do arranjo institucional, são dificultadores para a efetivação dos pactos? O Estado. Se o nível estadual de governo não quiser fazer, não acontece. Fatores contextuais são importantes. Fatores políticos, disputas político-partidárias entre municípios, entre estado e município. E fatores de natureza estrutural. Se não tem dinheiro, se não tem capacidade instalada, não tem como cooperar. Os municípios têm de complementar as tabelas do SUS com recursos próprios e eles só fazem isso para seus munícipes; não fazem a complementação para os munícipes de outros municípios. Os próprios conselhos municipais protestam contra isso. Os conselhos são municipais e não regionais. É extremamente complicado. Então, isso provoca várias diferenças.

Relatei alguns efeitos da trajetória da política de saúde sobre o SUS. Vamos pensar agora os efeitos que o SUS, uma vez tornado realidade, tem, incluídos aqueles efeitos políticos. É possível afirmar que ocorrem alterações na arena política da saúde com a introdução de novos atores, e é sobre eles, particularmente os gestores dos níveis subnacionais de governo, que quero falar. Os gestores hoje são pressionados a melhorar a saúde. Então - ainda que não seja por ideologia, mas por questões de sobrevivência política - eles são defensores de mais recursos para o SUS, de mais atenção para o SUS. Os conselheiros de saúde são novos atores constituídos na trajetória do SUS, e são também atores importantes. E alguns movimentos sociais em saúde, como o Saúde Mais Dez, agregam uma série de entidades e atores diversificados; a própria Frente Parlamentar de Saúde no Congresso tem certa atuação. Os prestadores de serviço - não por ideologia, mas por questão de sobrevivência também - 
são defensores do SUS. É lógico que eles são apoiadores ambíguos, porque servem a dois senhores, plano de saúde e o serviço público.

Outro efeito importante do SUS, apesar de a saúde ser o objeto de mais críticas... Todas as pesquisas de opinião incluem as perguntas: "Qual o maior problema do Brasil?", "O que tem que priorizar?". A saúde está na lista. No entanto, a expansão da assistência à saúde para todos os cidadãos produziu muitas expectativas, definiu comportamentos e gera demanda crescente por serviços de saúde. E, o mais importante, foi introjetado, de fato, que saúde é um direito do cidadão e um dever do Estado. Isso não é pouco. Apesar de todas as críticas, a saúde é considerada um direito do cidadão. Por isso se critica, porque não é exatamente aquilo que se quer. E isso se expressa, aliás, na crescente judicialização, que, do meu ponto de vista, é uma expressão do conflito entre direito coletivo e direito individual. A justiça funciona pelo direito do indivíduo e prejudica o direito coletivo; mas ela só é possível a partir do que está na Constituição, que é direito de todos e dever do Estado. É isso que lhe permite, é esse o argumento dos impetrantes, é esse o argumento dos juízes ao conceder as exceções.

Numa entrevista que me concedeu o deputado Marcos Pestana, do PSDB, médico ligado à Frente Parlamentar de Saúde, ele declarou: "Direitos ambiciosos e recursos escassos constituem uma combinação explosiva, que exige soluções". Se ele está falando isso, na minha avaliação, o SUS está de novo na agenda, o que me parece diferente do debate à época em que se comemoraram os vinte anos. Então eu me pergunto: Será que temos o prenúncio de um novo pacto em torno do SUS? Deixo isso para reflexão.

Temos, então, esse direito de cidadania, que pressiona por recursos, e o paradoxo é que ele não é uma prioridade política. Será que vai ser com essas pressões? Cresce o tensionamento decorrente das contradições desse sistema que parece atingir um nível crítico, que gera vários desdobramentos.

Para encerrar, quero lembrar a regulamentação da morosa emenda constitucional 29, que tramitou ao longo de 11 anos, com várias idas e vindas. O que foi votado frustrou as expectativas, mas seus desdobramentos foram interessantes e imediatos. O movimento nacional em defesa da saúde pública, por exemplo, juntou várias entidades e gerou o abaixoassinado Saúde Mais Dez, que em agosto conseguiu, após coletar assinaturas, encaminhar um projeto de iniciativa popular. No âmbito do Congresso, imediatamente após a regulamentação da emenda 29, foram formadas duas comissões especiais, uma no Senado outra na Câmara, para discutir o financiamento do SUS. Essa é a grande novidade. Há consenso de que financiamento do SUS é ruim e precisa ser resolvido. É complicado porque a discussão só está centrada nisso, mas já é algo, pois até pouco tempo atrás o problema era de gestão, não se falava em financiamento. Temos hoje um consenso político, o que é uma novidade.

Tivemos o movimento das ruas, caótico, anárquico, sem lideranças ou propostas agregadoras, mas que colocou também na agenda a questão da saúde, e provocou reações no Congresso Nacional; a agenda positiva dele foi para tramitar um projeto que estava lá desde o ano passado, parado, o dos 10\% da renda bruta da União para a saúde; e alterar um projeto em tramitação por mais de cinco anos, que era o de destinação dos royalties do petróleo: durante cinco anos não contemplou a saúde, mas depois do movimento das ruas entrou em votação e foi aprovado; teve a resposta do Executivo, o Mais Médicos... Assim, por uma confluência de fatores, o SUS ocupa a agenda governamental e pública, quer seja pelo crescimento das 
demandas sociais, quer seja pelo cálculo eleitoral, ou por ter uma janela de oportunidade até para opositores de governo criticarem, para quem quiser defender a radical separação ou tornar os sistemas complementares... O debate está aí, ainda obscuro do meu ponto de vista, mas está na agenda, ou seja, não dá para negar a questão.

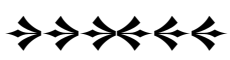

